\title{
Editorial
}

\section{C_-Journal of Carbon Research: A New Dawn}

\author{
Craig E. Banks \\ Faculty of Science and Engineering, School of Science and the Environment, \\ Division of Chemistry and Environmental Science, Manchester Metropolitan University, \\ Chester Street, Manchester M1 5GD, UK; E-Mail: C.Banks@mmu.ac.uk
}

Received: 23 December 2014 / Accepted: 24 December 2014 / Published: 29 December 2014

This new open access journal seeks to cover the whole field of Carbon Research under an open access policy that charges minimal fees for authors without compromising either publishing standards or quality. The Editors and MDPI are committed to the development of a journal that will be at the cutting edge of the subject.

The C-Journal of Carbon Research publishes articles concerning the whole field of Carbon Research and encourages a range of articles that encompasses comprehensive research articles, reviews, communications and letters. The journal encourages original and novel papers of either general or specialist importance. Since the C-Journal of Carbon Research is published as an online journal, there are no page restrictions. However, we distinguish between different types of publications: Short Communications contain either the key elements of a larger research project or preliminary results, and will be published rapidly. Full Articles are comprehensive reports on original research of the highest quality. Letters will discuss novel and thought-provoking scientific ideas and concepts that do not necessarily have to be fully proven (yet). Finally, high impact, authoritative, succinct and readable reviews across the breath of Carbon Research will also be published.

The goal of $C$-Journal of Carbon Research is to provide a global platform for publishing first-class, original research articles, which will undergo a qualified and rigorous, yet rapid peer-review process. A key selling point of the journal is that is it open access, which significantly enhances the efficiency and efficacy of scientific communication and breaks down boundaries, so as to allow access to readers from around the world.

I am excited about this new journal and I hope that it sparks your interest in the field of Carbon Research. We look forward to receiving some of your very best manuscripts for publication in this journal.

(C) 2014 by the authors; licensee MDPI, Basel, Switzerland. This article is an open access article distributed under the terms and conditions of the Creative Commons Attribution license (http://creativecommons.org/licenses/by/4.0/). 